\title{
Health-related quality of life in children with haemophilia in China: a 4-year follow- up prospective cohort study
}

\author{
Heng Zhang ${ }^{1}$, Jie Huang ${ }^{1}$, Xiaoyan Kong ${ }^{2}$, Gaoxiang $\mathrm{Ma}^{3}$ and Yongjun Fang ${ }^{1 *}$
}

\begin{abstract}
Background: Health-related quality of life (HRQoL) has been brought up for decades in haemophilia patients. However, no data to date are available about HRQoL in children with haemophilia using long-term follow up data. This nearly 4-year follow-up study aimed to assess the long-term HRQoL of haemophilia children.

Methods: A prospective cohort study among 42 children with haemophilia and their parents was conducted in August 2014 in a children's hospital; follow-up was completed in January 2018. Primary endpoint was the change in patient HRQoL evaluated by Canadian Haemophilia Outcomes-Kids' Life Assessment Tool (CHO-KLAT) from baseline to year 4; secondary endpoint was the impact of bleeding rates, physical activity restriction, financial burden and treatment (prophylaxis vs on-demand treatment) on HRQoL, as well as the impact of treatment on event-free survival.

Results: Totally 42 patients (mean age, 5.48[SD, 4.63] years) and 42 parents were included. 38 families completed 4year follow up. Patients reported a small increase in HRQoL from baseline to year 4 . The mean scores of child selfreport and parent proxy report of CHO-KLAT at baseline were $60.69(S D=20.28)$ and $61.01(S D=12.14)$, respectively. Scores at follow-up were $64.69(S D=13.71)$ and $65.33(S D=15.78)$, respectively. Haemophilia patients without physical activity restriction, living in urban areas, and receiving prophylactic treatment and home injection, had higher average values for HRQoL scores than the others. Bleeding rates were proportionally negatively correlated with HRQoL. Patients who had received prophylactic treatment had better event-free survival.

Conclusions: Haemophilia decreased HRQoL of patients, but this effect weakened after 4 years. HRQoL of children is influenced by severity of haemophilia, bleeding rates, physical activity restriction, financial burden and treatment. Prophylactic treatment is a key factor contributing to event-free survivor prognosis and the optimal form of therapy for childhood haemophilia.
\end{abstract}

Keywords: Haemophilia, Health related quality of life (HRQoL), The Canadian Haemophilia outcomes-kids' life assessment tool (CHO-KLAT), Prognosis

\section{Introduction}

Haemophilia, characterized by a bleeding disorder which primarily affects boys, is caused by an inherited deficiency of factor VIII (haemophilia A) or factor IX (haemophilia B) [1] and is associated with some

\footnotetext{
* Correspondence: fyj322@189.cn

Heng Zhang, Jie Huang and Xiaoyan Kong should be considered co-first authors.

Heng Zhang, Jie Huang and Xiaoyan Kong contributed equally to this work 'Department of Hematology and Oncology, Children's Hospital of Nanjing Medical University, Nanjing 210008, China

Full list of author information is available at the end of the article
}

symptoms such as spontaneous bruising, mucosal bleeding, joint bleeding, epistaxis, and severe or even fatal bleeding events like intracranial hemorrhages [1-3]. The prevalence of haemophilia A is currently estimated to be about 1 case per 5000 male live births annually, while 1 case of haemophilia B occurs per 30,000 [1]. Haemophilia is classified as severe $(<1 \%)$, moderate $(1-5 \%)$, or mild (5-40\%) with concentration of the factor measured [4]. This classification predicts the general risk of bleeding, a guide to the optimum management strategy and outcome predictions. Repeated joint bleeding can cause

(c) The Author(s). 2019 Open Access This article is distributed under the terms of the Creative Commons Attribution 4.0 International License (http://creativecommons.org/licenses/by/4.0/), which permits unrestricted use, distribution, and 
severe joint damage and pain, leading to disability [5]. Bleeding issues can be addressed as they occur (on-demand) or treatment can be given regularly to prevent bleeding (prophylaxis) [2, 5, 6]. Frequent hospital visits, injections and limited (sports) participation are common impairments for haemophilia patients, most of whom worry about bleeding, the need for invasive procedures (like blood tests and intravenous therapy) and the risk of permanent disability. Consequently, this disease and its treatment impact patients' health-related quality of life (HRQoL).

The concept of HRQoL was raised decades ago in haemophilia [7-10], and recent research outcomes emphasize the importance of considering HRQoL issues during decision making procedures surrounding the treatment of haemophilia [11-16]. HRQoL assessment provides a comprehensive vision of the patients' subjective feelings of function and well-being, and supports evaluation of therapeutic effect $[10,13,16]$. The Canadian Haemophilia Outcomes-Kids' Life Assessment Tool (CHO-KLAT) is a well-known disease-specific measure of HRQoL for childhood haemophilia patients $[8,17$, 18]. Socio-Economic Context (SEC) module is a questionnaire aiming at capturing the impact of social economic context on individual families [16]. We used the two measures to evaluate patients' HRQoL and explore the effect different local governments and types of insurance coverage have on haemophilia families [15].

There has been mounting evidence on the assessment of the quality of life (QoL) in haemophilia patients. However, a long period follow-up of HRQoL for childhood haemophilia remains rare. This prospective cohort study assessed the effect of haemophilia on patient-reported QoL from baseline to year 4. We also explored the effect of bleeding rates, physical activity restriction, financial burden and treatment (prophylaxis vs on-demand treatment) on HRQoL, as well as the impact of treatment on event-free survival. The study hypotheses were that haemophilia would affect patients' QoL, and HRQoL with haemophilia would have association with bleeding rates, financial burden and treatment.

\section{Methods}

\section{Patients}

A total of 42 subjects with haemophilia were recruited along with their parents from Nanjing Children's Hospital affiliated with Nanjing Medical University, between August 2014 and January 2018 Parents (or legal guardians of the subjects) were interviewed in person to collect clinical information. Among these 42 subjects, 37 had haemophilia A and the others had haemophilia B. The median age of subjects interviewed was 5.48 ( $\mathrm{SD}=$ 4.63). Patients with cognitive impairments, limited literacy skills, or other chronic illnesses such as cerebral palsy, diabetes, chronic immune thrombocytopenia, rheumatological disease and asthma were excluded from this study. According to the subjects' disease history, no subjects were excluded. Besides, those who did not complete $\mathrm{CHO}-\mathrm{KLAT}$ during the needed time-frame were considered ineligible for this research. Children aged 7 years old and older were asked to complete self-report versions of CHO-KLAT and self-report versions of SEC with little or no interruption from parents.

\section{Measures}

This is a 4-year prospective cohort follow-up study. Their early and recent responses were considered baseline data and follow-up data respectively. Events considered in event-free survival analysis were death, developing target joints (a target joint is a joint in which three or more spontaneous bleeds have occurred within a consecutive 6 month period [5]) and severe bleeding during the observation. CHO-KLAT is a disease-specific HRQoL measure that can be used in both clinical and home settings and has been updated to version 2.0 [8, 18]. It has been validated in several countries, including Canada, France, Germany, the Netherlands, Spain, the UK and China [14, 19] and consists of 2 questionnaires: one for children aged from 5 to 18 (child self-report), the other for parents on behalf of children aged from 2 to 18 (parent proxy report). This Chinese version includes all 35 original items from the CHO-KLAT. Scores have a range of 0 (worst) to 100 (best). There are no normative values of the CHO-KLAT. Higher scores mean better HRQoL. Children aged 7 years old and older, if literate, were asked to complete a self-report CHO-KLAT. Also, their parents were asked to complete a proxy CHO-KLAT on their behalf. The Chinese version has an additional unique SEC module, which consists of 9 questions covering information about stigma, opportunities for stable employment and access to treatment due to cost, etc. SEC scores have the same range as those of the original CHO-KLAT. The questionnaires were handed in hard copy to parents and patients in the clinic. Data were entered into an electronic database by researchers. All data were double entered to ensure accuracy. Data checks and cleaning were also performed. If more than $1 / 4$ of answers were not given in one report, its score would not be shown and it was rejected for the research.

\section{Statistical analysis}

Statistical analyses here were performed using Statistical Package for Social Science (version 22.0; SPSS). Qualitative variables were described in number and percentages and mean \pm SD, if quantitative. Preliminary analyses used paired sample t-tests to evaluate differences between baseline and follow-up patient-rated HRQL and 
one-sample t-tests to compare patient HRQL to normative values. ANOVA tests were used when comparing quantitative data between 2 groups or more. The Spearman coefficients were used when studying the relationship (direction and power) of quantitative variables simultaneously. The correlations between mean scores and bleeding rates were performed using correlation analysis. Kaplan-Meier survival curves were plotted, and the groups compared using the log-rank test to ascertain the relationship between treatment and prognosis. Cox regression model adjusted age, region of residence, severity and Family injection was used to calculate the $P$ value. The events we considered in KM analysis were death, target joints developing and severe bleeding. Two-sided $P$ values were selected and $P<0.05$ was considered statistically significant.

\section{Results}

\section{Patients' characteristics}

The frequency distributions of all subjects of the selected variables (the demographic, clinical, and biochemical data at enrolment, as well as treatment during follow-up) are provided in Table 1.18 cases (42.9\%) had a history of severe bleeding; 15 (35.7\%) suffered from intracranial hemorrhages and 11 (26.2\%) had a single target joint at the time of recruitment while 4 cases had multiple target joints. 8 cases had restricted physical activity at baseline. The restricted physical activity is defined as impact on daily life activities in the past one

Table 1 Frequency distribution of selected variables in Haemophilia patients

\begin{tabular}{|c|c|c|}
\hline \multirow[b]{2}{*}{ Variables } & \multicolumn{2}{|c|}{ Patients $(n=42)$} \\
\hline & $n$ & $\%$ \\
\hline Age patients (years), mean (SD) & $5.48(4.63)$ & \\
\hline \multicolumn{3}{|l|}{ Region of residence } \\
\hline Rural & 17 & 40.5 \\
\hline Urban & 25 & 59.5 \\
\hline \multicolumn{3}{|l|}{ Diagnosis } \\
\hline Haemophilia A & 37 & 88.1 \\
\hline Haemophilia B & 5 & 11.9 \\
\hline \multicolumn{3}{|l|}{ Severity } \\
\hline Severe & 14 & 33.3 \\
\hline Moderate & 24 & 57.2 \\
\hline Mild & 4 & 9.5 \\
\hline \multicolumn{3}{|l|}{ Type of treatment } \\
\hline On-demand treatment & 25 & 59.5 \\
\hline Prophylactic treatment & 17 & 40.5 \\
\hline \multicolumn{3}{|l|}{ Family injection } \\
\hline No & 30 & 71.43 \\
\hline Yes & 12 & 28.57 \\
\hline
\end{tabular}

month because the QoL questionnaires are filled according to participants' situation during the past one month. None of the patients were known to have an inhibitor at enrolment. All the 4 mild hemophilia boys, 16 of 24 children with moderate disease, and 5 of 14 with severe disease received an on-demand therapy, while the others were subjected to prophylactic treatment at medium dose $(15-30 \mathrm{U} / \mathrm{kg}$, two or three times a week). During the follow-up, 4 patients were lost ( 2 cases had a history of target joints). Only 1 case suffered from severe bleeding (urinary system) and 4 cases developed target joints. 4 cases with target joints at baseline got better (the target joint stopped experiencing symptoms). Of all cases at the endpoint, 13 cases had target joints; however, merely 7 cases had restricted physical activity. One patient had an inhibitor.

\section{CHO-KLAT and SEC scores of children}

The results of this comparison are shown in Table 2. At baseline, all parents on behalf of their children completed the parent version of the CHO-KLAT and SEC while only 12 patients were old enough to complete it independently. The mean scores for the CHO-KLAT child/proxy report were $60.69(\mathrm{SD}=20.28)$ and 61.01 $(\mathrm{SD}=12.14)$ respectively. For the $\mathrm{SEC}$, the mean scores were $60.62(\mathrm{SD}=14.32)$ and $56.43(\mathrm{SD}=12.59)$ respectively. There were no significant differences between the scores of 12 proxy and child self-reports in CHO-KLAT or SEC $(p=0.440$ and $p=0.275$, respectively). At follow-up, 38 parents completed the scales. 18 children were old enough to complete the child self-reports scales independently. The mean score for the CHO-KLAT child self-report and parent proxy report were 64.93 $(\mathrm{SD}=13.71)$ and $65.33(\mathrm{SD}=15.78)$ respectively. The child/proxy report SEC scores were $65.09(\mathrm{SD}=15.36)$ and $61.62(\mathrm{SD}=17.46)$. Statistical significance was not achieved between the scores of 18 proxy and child self-reports in CHO-KLAT or SEC $(p=0.694$ and $p=$ 0.522 , respectively). Scores at follow-up were higher than those at baseline in both CHO-KLAT and SEC but no statistical significance was observed.

No major relation was found between the two types of haemophilia and the scores of the child/proxy reports. Urban patients had significantly higher scores than rural patients in CHO-KLAT. Considering urban patients had higher insurance coverage than rural patients $(85 \%$ vs $30-75 \%$ ), financial status would be an explanation for the above difference, which was also proved by the SEC results in Table 3. As with severity of disease, the statistical difference appeared only in the CHO-KLAT parent proxy report group $(p=0.037)$ and SEC child self-report group $(p=0.040)$ at baseline. The mean scores of CHO-KLAT and SEC child/proxy reports in the prophylactic group were significantly higher than those in the 
Table 2 Scores of CHOKLAT and SEC for Child/Proxy groups

\begin{tabular}{|c|c|c|c|c|c|c|c|c|}
\hline \multirow[t]{2}{*}{ HRQoL Scales } & \multirow[t]{2}{*}{ N } & \multicolumn{3}{|l|}{ Baseline Scores } & \multirow[t]{2}{*}{$N$} & \multicolumn{3}{|l|}{ Follow-up Scores } \\
\hline & & Mean values (SD) & $\mathrm{MINI}$ & MAX & & Mean values (SD) & $\mathrm{MINI}$ & MAX \\
\hline \multicolumn{9}{|l|}{ CHOKLAT } \\
\hline Child self-report & 12 & $60.69(20.28)$ & 25.78 & 93.38 & 18 & $64.69(13.71)$ & 33.87 & 83.93 \\
\hline Parent proxy report & 42 & $61.01(12.14)$ & 25.76 & 79.00 & 38 & $65.33(15.78)$ & 19.70 & 86.67 \\
\hline \multicolumn{9}{|l|}{ SEC } \\
\hline Child self-report & 12 & $60.62(14.32)$ & 36.11 & 90.63 & 18 & $65.09(15.36)$ & 38.89 & 87.50 \\
\hline Parent proxy report & 42 & $56.43(12.59)$ & 31.25 & 93.75 & 38 & $61.62(17.46)$ & 30.56 & 96.88 \\
\hline
\end{tabular}

on-demand group, especially for the parent proxy reports for CHO-KLAT and SEC. Patients who had received home injection got higher QoL at follow-up.

The mean of annual bleeding rate (ABR) and annual joint bleeding rate $(\mathrm{AJBR})$ were $7.29(\mathrm{SD}=9.73$; ranging from 0 to 48$), 2.86(\mathrm{SD}=5.82$; ranging from 0 to 24$)$ at baseline, respectively, and $8.50(\mathrm{SD}=10.16$; ranging from 0 to 40 ), 4.50 ( $\mathrm{SD}=7.64$; ranging from 0 to 40 ) at follow-up, respectively. The amount of change during this follow-up study in ABR $(\triangle \mathrm{ABR})$ and AJBR $(\triangle \mathrm{AJBR})$ was 2.71 ( $\mathrm{SD}=9.40$; ranging from -20 to 30$)$ and 1.89 ( $\mathrm{SD}=8.86$; ranging from -22 to 38 ).

\section{Correlational analyses}

Table 4 describes the correlations between mean scores and bleeding rates. As expected, a negative relation was apparent between ABR, AJBR, $\triangle \mathrm{ABR}, \triangle \mathrm{AJBR}$ and scores. The parent proxy report CHO-KLAT was most strongly related to the ABR $(r=-0.609, p=0.000)$, AJBR $(r=-$ $0.353, p=0.030)$ and $\triangle \mathrm{ABR}(r=-0.573, p=0.000)$. Additionally, a significantly negative correlation was found between SEC parent proxy report scores and ABR, $\triangle \mathrm{ABR}, \triangle \mathrm{AJBR}(r=-0.569, p=0.000$ and $r=-0.538, p=$ 0.000 and $r=-0.381 p=0.018$, respectively). There was no correlation between bleeding rates and child self-report scores of CHO-KLAT. Pearson bivariate correlations revealed positive significant association between SEC and patient HRQoL regardless of baseline or follow-up. The follow-up results showed that child self-reports had higher correlations with parent proxy reports in CHO-KLAT $(r=0.772)$ and SEC $(r=0.690)$. The correlation analysis indicated that SEC showed intimate correlations with the CHO-KLAT, suggesting the SEC module was necessary for Chinese patients.

\section{Prognosis analyses}

The events we considered here were death, target joints developing and severe bleeding. Throughout the follow up, 5 special cases were recorded. One of them suffered from severe bleeding (urinary system) and the rest developed new target joints. The 5 cases observed were all haemophilia $\mathrm{A}$, severe in 3 , moderate in 1 and mild in 1 .
When it comes to treatment assessment, 4 cases received on-demand treatment whereas only 1 case received prophylaxis treatment. In a comprehensive multivariate Cox regression analysis including age and region of residence, the treating method remained an independent prognostic variable for haemophilia $(P=$ 0.036, Fig. 1). Prophylaxis treatment is a key factor contributing to prognosis.

\section{Discussion}

This study demonstrated that haemophilia decreased HRQoL of patients, but this effect weakened at year 4 compared with the baseline, the primary outcome. In addition, exploratory secondary outcomes also showed that HRQoL was influenced by bleeding rates, physical activity restriction, financial burden and treatment. Prophylactic treatment was a key factor contributing to event-free survivor prognosis and an optimal therapy for haemophilia patients.

To our knowledge, this was the first long-time follow-up prospective cohort study to estimate the potential factor influencing haemophilia HRQoL and to provide a direct comparison of prognosis for treatment (on-demand vs prophylaxis treatment) in haemophiliac children in China. We found that haemophilia could have adverse effects on functioning and well-being of children. The children and their parents usually had impaired HRQoL because of the limitations imposed on daily activity and social, emotional functioning. Facing unpredictable bleeding events, the families showed greater concern, which affected the whole families' QoL as a consequence. However, when the children grew up, they could be less worried, with a full knowledge of haemophilia and better preparation for bleeding events. As life expectancy among haemophilia has increased, stable partnerships have become prominent features in the life planning of haemophilia, also improving HRQoL.

Mean value of CHO-KLAT parent proxy reports (64.69, SD $=13.71)$ was similar to child self-reports (65.33, SD $=15.78$ ) without statistically significant differences. This result is comparable to the study of L. Tang 


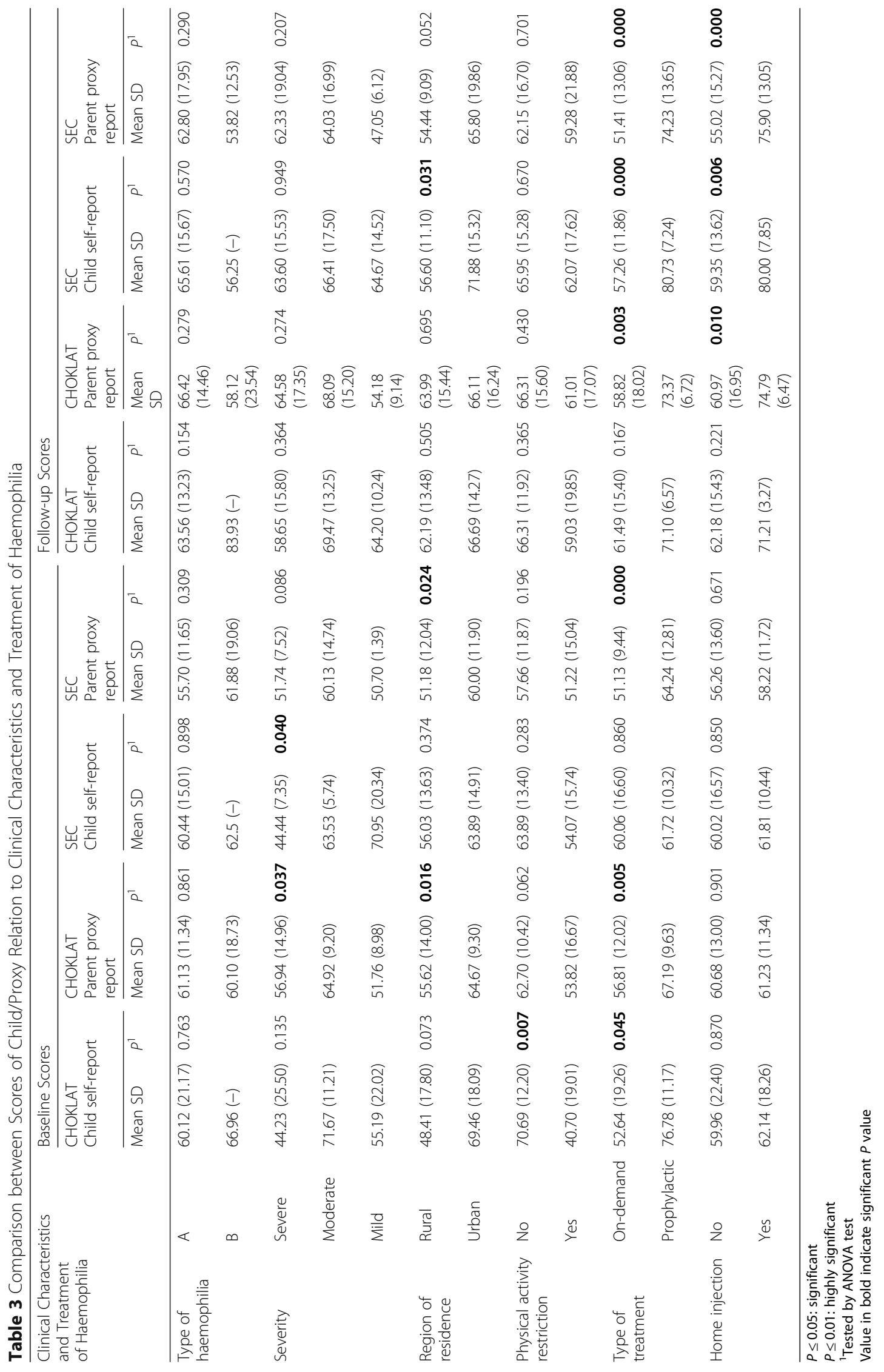


Table 4 Correlations between Scores at follow-up and ABR and AJBR

\begin{tabular}{|c|c|c|c|c|c|c|c|c|}
\hline & \multicolumn{2}{|c|}{$\begin{array}{l}\text { CHOKLAT } \\
\text { Child self-report }\end{array}$} & \multicolumn{2}{|c|}{$\begin{array}{l}\text { CHOKLAT } \\
\text { Parent proxy report }\end{array}$} & \multicolumn{2}{|c|}{$\begin{array}{l}\text { SEC } \\
\text { Child self-report }\end{array}$} & \multicolumn{2}{|c|}{$\begin{array}{l}\text { SEC } \\
\text { Parent proxy report }\end{array}$} \\
\hline & $\bar{r}$ & $P^{\prime}$ & $r$ & $p^{1}$ & $r$ & $P^{\prime}$ & $\bar{r}$ & $P^{1}$ \\
\hline$\overline{\mathrm{ABR}^{1}}$ & -0.188 & 0.454 & $-0.609^{2}$ & $0.000^{2}$ & -0.241 & 0.336 & $-0.569^{2}$ & $0.000^{2}$ \\
\hline $\mathrm{AJBR}^{1}$ & -0.112 & 0.659 & $-0.353^{3}$ & $0.030^{3}$ & -0.014 & $0.955^{3}$ & -0.251 & 0.128 \\
\hline$\Delta \mathrm{ABR}^{1}$ & -0.314 & 0.205 & $-0.573^{2}$ & $0.000^{2}$ & $-0.537^{3}$ & $0.021^{3}$ & $-0.538^{2}$ & $0.000^{2}$ \\
\hline$\Delta \mathrm{AJBR}^{1}$ & -0.129 & 0.610 & -0.273 & 0.097 & -0.287 & 0.249 & $-0.381^{3}$ & $0.018^{3}$ \\
\hline
\end{tabular}

$A B R$ annualized bleeding rate, $A J B R$ annualized joint bleeding rate

${ }^{1}$ Correlated by the Spearman correlation

${ }^{2}$ Correlation is significant at the 0.01 level (2-tailed)

${ }^{3}$ Correlation is significant at the 0.05 level (2-tailed)

Value in bold indicate significant $P$ value

et al. in China [16], but the scores were significantly lower than reported scores in developed countries such as Canada [18](75.4, $\mathrm{SD}=12.0)$, Germany $(71.5, \mathrm{SD}=$ 13.3), France (76.7, $\mathrm{SD}=9.7)$, Spain $(78.4, \mathrm{SD}=10.8)$ and the Netherlands $(82.8, \mathrm{SD}=8.4)$ [14], where prophylaxis is taken as the standard treatment of haemophilia with severe haemophilia. This difference indicates that economic development may have a considerable effect on the QoL of haemophilia. In this study, haemophilia patients living in urban areas had higher average HRQoL values than in rural areas. As is known, the high factor of consumption and cost presents a major barrier to haemophilia treatment in developing countries [20]. Patients living in urban areas like Nanjing city have a higher medical insurance covering $85 \%$ of the total medical cost. But in rural areas, patients are more constrained by their financial status with a lower medical insurance coverage, varying from 30 to $75 \%$ in different areas. Financial burden affects patients' HRQoL. Meanwhile, the SEC, which added important additional information related to the social and economic context of the patient, also supported this conclusion.

QoL is a subjective assessment affected by multiple factors. As can be seen from Table 4, bleeding rates were proportionally negatively correlated with HRQoL. Furthermore, the obvious correlation in the parents' reports showed their greater concern towards the bleeding issue. Repeated joint bleeding, depending on the severity of the disease, can cause severe joint damage, pain, and disability [21]. It might be expected that individuals disabled by dysfunctional joints and chronic pain would encounter problems in landing a job, seeking a partner, or having children. Therefore, most of the patients and their parents feel anxiety towards their uncertain future.

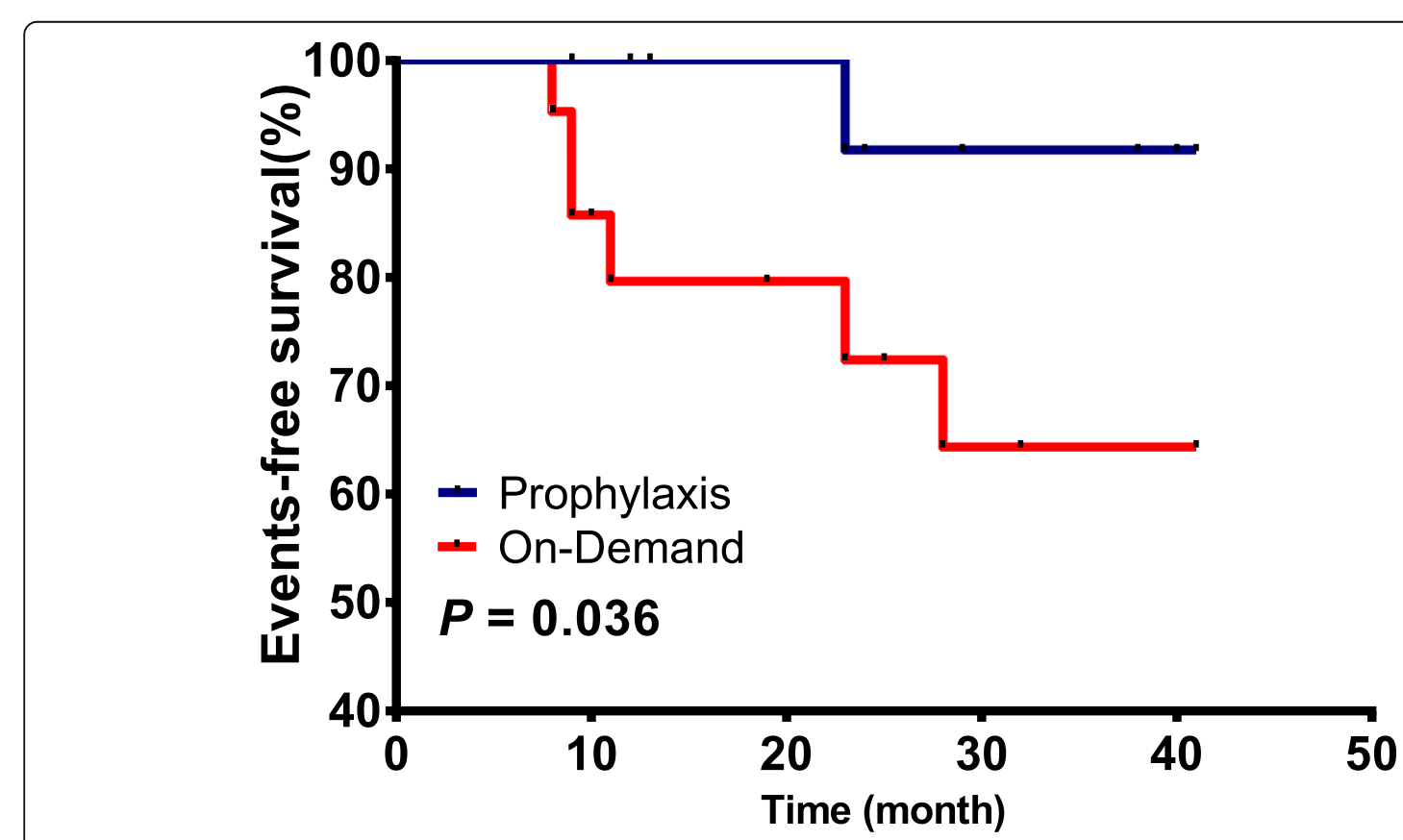

Fig. 1 Kaplan-Meier Survival Curves by Treating Method. The treating method curves were significantly different from each other $(p=0.036)$ 
Many daily activities are limited to avoid bleeding events, which might influence the children's QoL as well. At the same time, patients who had received home injection got higher scores, indicating that timely solution of factor replacement could reduce their concern, improving QoL.

Our data showed that HRQoL scores were higher in children who had received prophylaxis compared to on-demand treatment. Earlier implementation of prophylaxis treatment is known to decrease bleeding rates to protect joints from damage by routine replacement of deficient clotting factor [6,21]. Our patients in this study received medium dose prophylaxis treatment, which was used since the 1960s in Netherlands with a dose of $15-25 \mathrm{IU} / \mathrm{kg}$ every other day or three times a week [22]. Most of the patients began prophylaxis when they were younger than 3 , which may protect and improve HRQoL. Table 4 reveals an inconsistency between the average scores of the parent proxy report and child self-report groups. As Rama Zilber mentioned, the basic concern of all parents was the health and future of their children [23]. Yet the life experiences and inner lives of children were different from those of the adults, resulting them having different priorities, as reflected in the scores. No significant relation was found between the type of haemophilia and HRQoL. The effect of an inhibitor was not addressed in the study since there was only 1 respondent.

This work also demonstrated that 17 patients undergoing primary prophylaxis treatment took a lower risk to develop target joints and suffer severe bleeding. Many studies have revealed early high-dose prophylaxis provides excellent long-term clinical outcomes [24]. The World Health Organization (WHO) and the World Federation of Hemophilia (WFH) suggest that initiating prophylactic treatment at an early age is the optimal form of therapy for a child with severe haemophilia [2, 5]. 13 of the 17 patients in this study had received prophylactic treatment before the age of 3 . Only 1 case in the prophylactic treatment group developed a target joint during the follow-up period, and no one suffered from severe bleeding.

Some limitations of the study should be addressed. Firstly, the study was limited by a small sample size of subjects. Children need to be older than 7 to finish the self-reporting part independently, yet the median age of haemophilia children here was 5.48 years old, which severely reduces the number of qualified subjects. It is essential to validate the results in a larger size of subjects. Secondly, this study focused only on the factor replacement treatment rather than some new treatment. Chinese parents prefer taking traditional Chinese medicines concurrently. Future research should take the limitations above into account.

\section{Conclusions}

Overall, haemophilia has an impact on the HRQoL of patients, who had a lower increase in HRQoL after 4 years. HRQoL of haemophilia is influenced by severity of disease, bleeding rates, physical activity restriction, financial burden and treatment. Prophylactic treatment is an optimal therapy for childhood haemophilia and a key factor contributing to event-free survival prognosis.

\section{Abbreviations \\ ABR: Annual bleeding rate; AJBR: Annual joint bleeding rate; $\mathrm{CHO}-$ KLAT: Canadian Haemophilia Outcomes-Kids' Life Assessment Tool; HRQoL: Health-related Quality of Life; SEC: Socio-Economic Context; SPSS: Statistical Package for Social Science}

\section{Acknowledgments}

The authors would like to express their appreciation to all participants of this study and wish to acknowledge my English teacher Mr. Richard Shi and my husband Mr. Mingjue Ge for critical editing of English grammar and syntax of the manuscript.

\section{Funding}

This research was jointly supported by Medical Science and technology development Foundation, Nanjing Medical University (CN) (2015NJMU064, 2017NJMU 055), National Natural Science Foundation of China (CN) (81670155, 81602913), Natural Science Foundation of Jiangsu Province (CN) (BK20150085), Jiangsu Provincial Commission of Health and Family Planning (CN) (Z201611) and Medical Science and Technology Development Foundation, Nanjing Municipality Health Bureau (CN) (QRX17164, YKK15140).

\section{Availability of data and materials}

The datasets generated and/or analyzed during the current study are not publicly available to preserve the privacy of the participants but are available from the corresponding author on reasonable request.

\section{Authors' contributions}

Yongjun Fang and Heng Zhang made substantial contributions to conception and design. Heng Zhang drafted the manuscript and collected the data. Jie Huang and Xiaoyan Kong worked as general supervisions of the research group. Gaoxiang Ma gave statistical support. All authors read and approved the final manuscript.

\section{Ethics approval and consent to participate}

The research protocol was approved by the Medical Ethics Committee of Nanjing Children's Hospital affiliated to Nanjing Medical University. Written informed consent was obtained from the parents (or legal guardians) of all study subjects at the time of enrollment into this study.

Consent for publication

Not applicable.

\section{Competing interests}

The authors declare that they have no conflict of interest.

\section{Publisher's Note}

Springer Nature remains neutral with regard to jurisdictional claims in published maps and institutional affiliations.

\section{Author details}

'Department of Hematology and Oncology, Children's Hospital of Nanjing Medical University, Nanjing 210008, China. ${ }^{2}$ Department of anesthesiology, Children's Hospital of Nanjing Medical University, Nanjing 210008, China. ${ }^{3}$ School of Traditional Chinese Pharmacy, China Pharmaceutical University, Nanjing 211198, China. 
Received: 16 May 2018 Accepted: 7 January 2019

Published online: 06 February 2019

\section{References}

1. Mannucci PM, Tuddenham EG. The hemophilias--from royal genes to gene therapy. N Engl J Med. 2001;344:1773-9.

2. Ljung R, Gretenkort Andersson N. The current status of prophylactic replacement therapy in children and adults with haemophilia. $\mathrm{Br}$ J Haematol. 2015;169:777-86.

3. Ljung RC. Intracranial haemorrhage in haemophilia a and B. Br J Haematol. 2008;140:378-84.

4. White GC 2nd, Rosendaal F, Aledort LM, Lusher JM, Rothschild C, Ingerslev J, Factor $\mathrm{V}$, Factor IXS. Definitions in hemophilia. Recommendation of the scientific subcommittee on factor VIII and factor IX of the scientific and standardization committee of the International Society on Thrombosis and Haemostasis. Thromb Haemost. 2001;85:560.

5. Srivastava A, Brewer AK, Mauser-Bunschoten EP, Key NS, Kitchen S, Llinas A, Ludlam CA, Mahlangu JN, Mulder K, Poon MC, et al. Guidelines for the management of hemophilia. Haemophilia. 2013;19:e1-47.

6. Manco-Johnson MJ, Abshire TC, Shapiro AD, Riske B, Hacker MR, Kilcoyne R, Ingram JD, Manco-Johnson ML, Funk S, Jacobson L, et al. Prophylaxis versus episodic treatment to prevent joint disease in boys with severe hemophilia. N Engl J Med. 2007;357:535-44

7. Remor E, Young NL, Von Mackensen S, Lopatina EG. Disease-specific qualityof-life measurement tools for haemophilia patients. Haemophilia. 2004; 10(Suppl 4):30-4.

8. Young NL, Bradley CS, Wakefield CD, Barnard D, Blanchette VS, McCusker PJ. How well does the Canadian Haemophilia outcomes-Kids' life assessment tool (CHO-KLAT) measure the quality of life of boys with haemophilia? Pediatr Blood Cancer. 2006;47:305-11.

9. Broderick CR, Herbert RD, Latimer J, Curtin JA. Fitness and quality of life in children with haemophilia. Haemophilia. 2010;16:118-23.

10. van der Net J, Vos RC, Engelbert RH, van den Berg MH, Helders PJ, Takken T. Physical fitness, functional ability and quality of life in children with severe haemophilia: a pilot study. Haemophilia. 2006;12:494-9.

11. St-Louis J, Urajnik DJ, Menard F, Cloutier S, Klaassen RJ, Ritchie B, Rivard GE, Warner M, Blanchette V, Young NL. Generic and disease-specific quality of life among youth and young men with hemophilia in Canada. BMC Hematol. 2016;16:13.

12. Krasuska M, Riva S, Fava L, von Mackensen S, Bullinger M. Linking quality-oflife measures using the international classification of functioning, disability and health and the international classification of functioning, disability and health-children and youth version in chronic health conditions: the example of young people with hemophilia. Am J Phys Med Rehabil. 2012;91:S74-83.

13. Taha MY, Hassan MK. Health-related quality of life in children and adolescents with hemophilia in Basra, southern Iraq. J Pediatr Hematol Oncol. 2014;36:179-84.

14. McCusker PJ, Fischer K, Holzhauer S, Meunier S, Altisent C, Grainger JD, Blanchette VS, Burke TA, Wakefield C, Young NL. International cross-cultural validation study of the Canadian haemophilia outcomes: kids' life assessment tool. Haemophilia. 2015;21:351-7.

15. Wu R, Sun J, Xiao J, Liu Y, Xue F, Wang H, Tang L, Zhao Y, Li K, Yang R, et al. A prospective study of health-related quality of life of boys with severe haemophilia a in China: comparing on-demand to prophylaxis treatment. Haemophilia. 2017;23:430-6.

16. Tang L, Xu W, Li CG, Hou F, Feng XQ, Wang H, Li XJ, Li WL, Liu JP, Sun LR, et al. Describing the quality of life of boys with haemophilia in China: results of a multicentre study using the CHO-KLAT. Haemophilia. 2018;24: 113-9.

17. Bradley CS, Bullinger M, McCusker PJ, Wakefield CD, Blanchette VS, Young $\mathrm{NL}$. Comparing two measures of quality of life for children with haemophilia: the CHO-KLAT and the Haemo-QoL. Haemophilia. 2006;12: 643-53.

18. Young NL, Wakefield C, Burke TA, Ray R, McCusker PJ, Blanchette V. Updating the Canadian hemophilia outcomes-kids life assessment tool (CHO-KLAT Version2.0). Value Health. 2013;16:837-41.

19. Wu R, Zhang J, Luke KH, Wu X, Burke T, Tang L, Poon MC, Li X, Zhou M, Sun $J$, et al. Cross-cultural adaptation of the CHO-KLAT for boys with hemophilia in rural and urban China. Health Qual Life Outcomes. 2012;10:112.

20. Wu R, Luke KH. The benefit of low dose prophylaxis in the treatment of hemophilia: a focus on China. Expert Rev Hematol. 2017;10:995-1004.
21. Manco-Johnson MJ, Soucie JM, Gill JC. Joint outcomes Committee of the Universal Data Collection USHTCN: prophylaxis usage, bleeding rates, and joint outcomes of hemophilia, 1999 to 2010: a surveillance project. Blood. 2017:129:2368-74.

22. Ljung R. Prophylactic therapy in haemophilia. Blood Rev. 2009;23:267-74.

23. Zilber R, Bortz AP, Yacobovich J, Yaniv I, Tamary H. Analysis of health-related quality of life in children with immune thrombocytopenia and their parents using the kids' ITP tools. J Pediatr Hematol Oncol. 2012;34:2-5.

24. Vepsalainen $K$, Riikonen $P$, Lassila $R$, Arola $M$, Huttunen $P$, Lahteenmaki $P$, Mottonen M, Selander T, Martikainen J. Long-term clinical and economic outcomes in previously untreated paediatric patients with severe haemophilia a: a nationwide real-world study with 700 person-years. Haemophilia. 2018.
Ready to submit your research? Choose BMC and benefit from:

- fast, convenient online submission

- thorough peer review by experienced researchers in your field

- rapid publication on acceptance

- support for research data, including large and complex data types

- gold Open Access which fosters wider collaboration and increased citations

- maximum visibility for your research: over $100 \mathrm{M}$ website views per year

At $\mathrm{BMC}$, research is always in progress.

Learn more biomedcentral.com/submissions 